\title{
Evans blue as counterstain in the demonstration of muscle antibodies by immunofluorescence in myasthenia gravis
}

\author{
O. CLOSS ${ }^{1}$ AND J. A. AARLI
}

From the Department of Microbiology, The Gade Institute, and Department of Neurology, School of Medicine, University of Bergen, Bergen, Norway

SYNOPSIS The binding of muscle antibodies to skeletal muscle was studied by immunofluorescence techniques. The non-specific fluorescence was not significantly reduced by absorption of the conjugate by tissue powder but was abolished by counterstaining with a $0 \cdot 1 \%$ Evans blue. Possible explanations for this effect are discussed. By this method, immunofluorescence may become more useful in the demonstration of muscle antibodies.

The Fc portion of the IgG molecule is responsible for non-specific binding of human immunoglobulin of skeletal muscle. This binding can be reduced by using $\mathrm{F}\left(\mathrm{ab}^{\prime}\right)_{2}$ fragments of IgG prepared by pepsin digestion (Aarli, 1970; Aarli and Closs, 1972). For immunofluorescence, the use of conjugated pepsindigested immunoglobulin does not completely abolish staining due to non-specific binding of immunoglobulin.

In attempts to localize a citric acid-soluble antigen in striated muscle, the presence of this nonspecific staining was a cause for concern. Nichols and McComb (1962) showed that counterstaining with Evans blue greatly reduced unwanted fluorescence in human conjunctival scrapings. The present paper describes the successful use of Evans blue in reducing non-specific fluorescence of skeletal muscle.

\section{Materials and Methods}

\section{SERA}

Sera from patients with myasthenia gravis were collected at the Department of Neurology. Normal human serum was obtained by collecting a pool of sera from blood donors.

Gamma globulin $16.5 \%$ (AB Kabi, Stockholm, Sweden) was used as the source of human Ig in preparation of normal $F\left(a^{\prime}\right)_{2}$ fragments. Rabbit antiserum to human IgG was produced according to Larsen and Tönder (1969).

'Present address: Institute for Experimental Medical Research, Ullevaal Hospital, Oslo, 1, Norway.

Received for publication 23 August 1973.
PREPARATION OF F(ab') ${ }_{2}$ FRAGMENTS Immunoglobulin (Ig) was precipitated from serum in $1.33 \mathrm{M} \mathrm{Na}\left(\mathrm{NH}_{4}\right)_{2} \mathrm{SO}_{4}$. The precipitate was dise solved in isotonic phosphate-buffered saline, $\mathrm{pH} 7.8$ (PBS). The solution was first dialysed against PBŞ for 48 hours at $4{ }^{\circ} \mathrm{C}$ with several changes of buffee and then against $0 \cdot 1 \mathrm{M}$ acetate buffer, pH $4 \cdot 1$.

For pepsin digestion of Ig, an enzyme/protein ratio of 2:100 was used (pepsin twice crystallized, Sigma Chemical Company, lot 69B-2000). Digestion was performed at $37^{\circ} \mathrm{C}$ for 24 hours. Finally, the $\mathrm{pH}$ was raised to 8.0 by dialysis. Reducing agents were not used. Protein concentration was estimated by a modified Folin-Ciocalteau method (Lowry, Rosebrough, Farr, and Randall, 1951).

\section{PREPARATION OF CONJUGATES}

$F\left(a b^{\prime}\right)_{2}$ fragments, prepared from normal human Ig, serum myasthenia gravis 12 , and rabbit antihuman IgG were conjugated with fluorescein isothiocyanate (FITC) at $25^{\circ} \mathrm{C}$ and $\mathrm{pH} 9.5,12.5 \mu \mathrm{g}$ FITC being added per mg protein. After 30 minutes' continuous stirring, the temperature of the mixture was reduced to $4^{\circ} \mathrm{C}$ and unbound dye removed by passage through a Sephadex G-15 column. The OD ratio $\frac{\mathrm{OD}_{280 \mathrm{~nm}}}{\mathrm{OD}_{495} \mathrm{~nm}}$ exceeded 4 for all conjugates. The conjugates were diluted in PBS to a protein concentration of $1.5 \mathrm{mg} / \mathrm{ml}$. To reduce non-specific staining a few portions, each of $0.5 \mathrm{ml}$, of conjugated antiserum were absorbed with $100 \mathrm{mg}$ (dry weight) washed, lyophilized, rabbit skeletal muscle at $4^{\circ} \mathrm{C}$ for 16 
hours. Portions of conjugated myasthenia gravis 12 sera were similarly absorbed with $100 \mathrm{mg}$ liver or kidney tissue.

COLLECTION OF TISSUE AND PREPARATION OF TISSUE SECTIONS

Diaphragm, heart, kidney, liver, and skeletal muscle tissues were removed from healthy, non-immunized rabbits and immediately frozen in acetone/dry ice. Muscle fascicles were stretched in situ by fixing to small wooden sticks before removal. Sections, 4-6 $\mu$ thick, were prepared in a cryostat microtome. The sections were air-dried and fixed in cold acetone for five minutes.

STAINING PROCEDURE

\section{Direct technique}

The sections were incubated with conjugate for 30 minutes at room temperature and washed in PBS for 60 minutes with five changes of buffer.

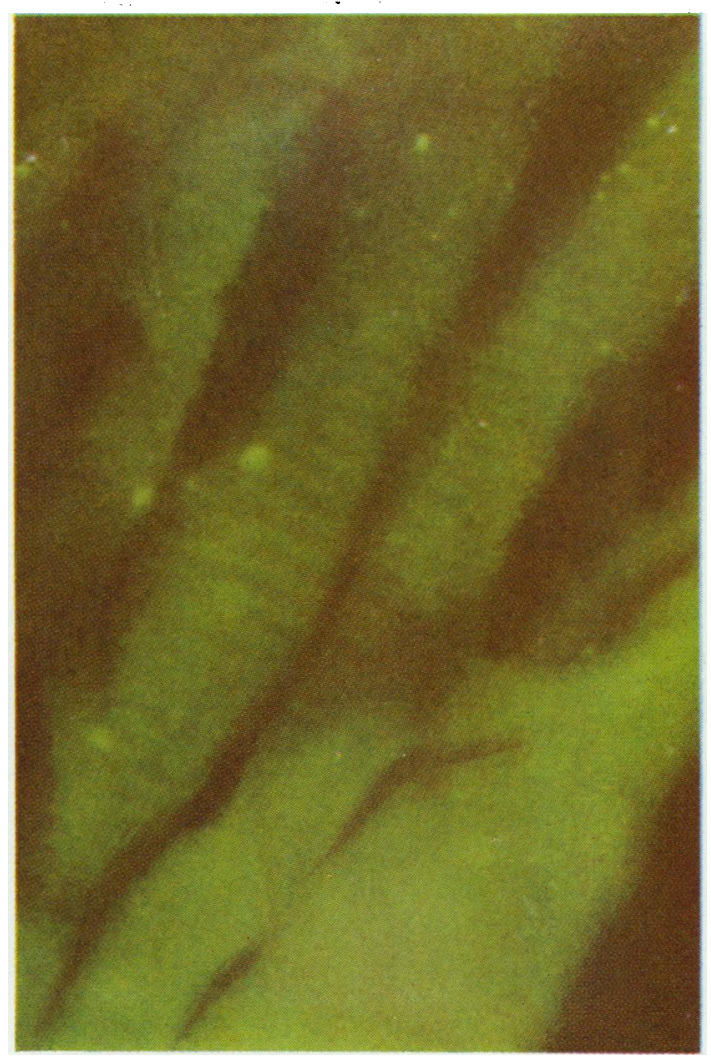

Fig 1a Rabbit diaphragm treated with normal human serum diluted 1:32 and fluorescein-labelled antihuman gamma globulin diluted 1: 16. $1200 \times$.
Indirect immunofluorescence technique

Unlabelled serum, diluted as indicated, was applied for 30 minutes at room temperature. Unbound protein was removed by washing in PBS for 30 minutes with five changes of buffer. Labelled $F\left(a b^{\prime}\right)_{2}$ rabbit antihuman IgG was then applied for 30 minutes, and the washing procedure repeated.

\section{Counterstaining with Evans blue}

The slides were submerged in a $0 \cdot 1 \%$ solution of Evans blue in distilled water for five minutes before washing in PBS for 10 minutes with three changes of buffer.

\section{FLUORESCENCE MICROSCOPY}

A Leitz Orthoplan microscope was used with Opak equipment for incident illumination. Light source: Phillips HB 200 mercury lamp. Primary filters: BG $12,3+1 \mathrm{~mm}, \mathrm{~A} 1470$, and dichromatic mirror TK 495. Secondary filter: K 530.

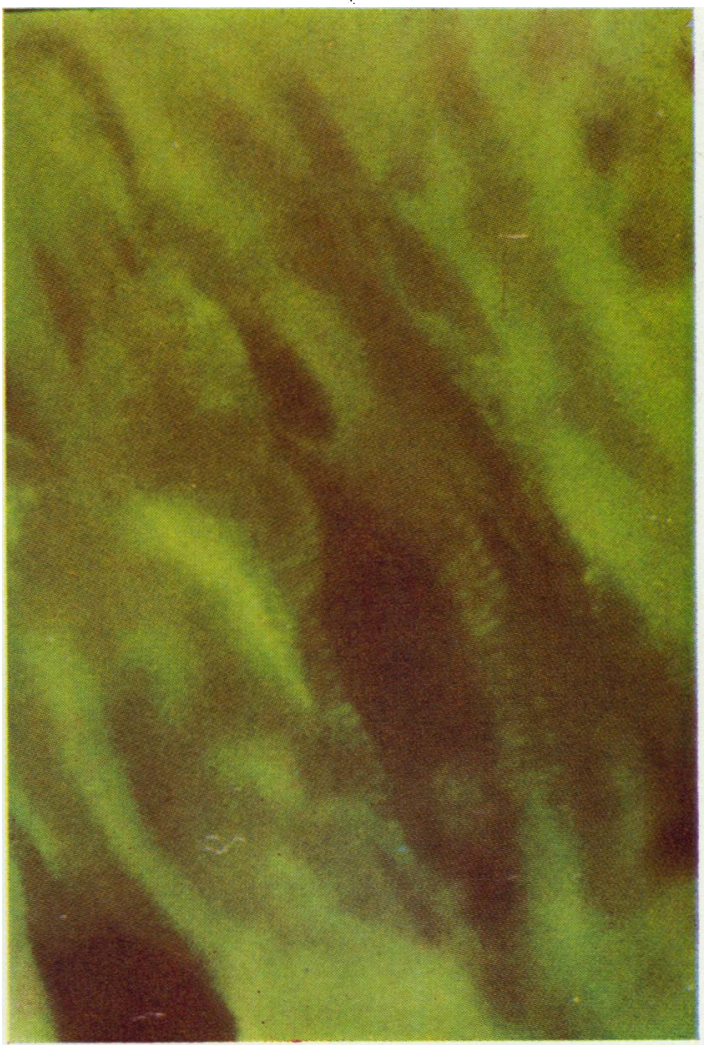

Fig 1b Rabbit diaphragm treated with serum myasthenia gravis 12 diluted 1:32 and fuorescein-labelled antihuman gamma globulin diluted 1: 16. $1200 \times$. 
The intensity of fluorescence was recorded as $(+)$ very weak, + weak, ++ moderate,+++ strong. Interpolations such as $+(+)$ were frequently made.

PREPARATION OF ANTIGEN

The citric acid-soluble antigen (CAS) was prepared according to Espinosa and Kaplan (1968). The antigen used in the blocking experiment had a protein content of $0.35 \mathrm{mg} / \mathrm{ml}$ and gave a haemagglutination inhibition titre of 2048 (Aarli, 1972a).

INDIRECT HAEMAGGLUTINATION TEST FOR MUSCLE ANTIBODIES

This test was carried out as described by Aarli (1972a).

\section{Results}

When using the indirect immunofluorescence technique, normal human serum gave a cross-striational

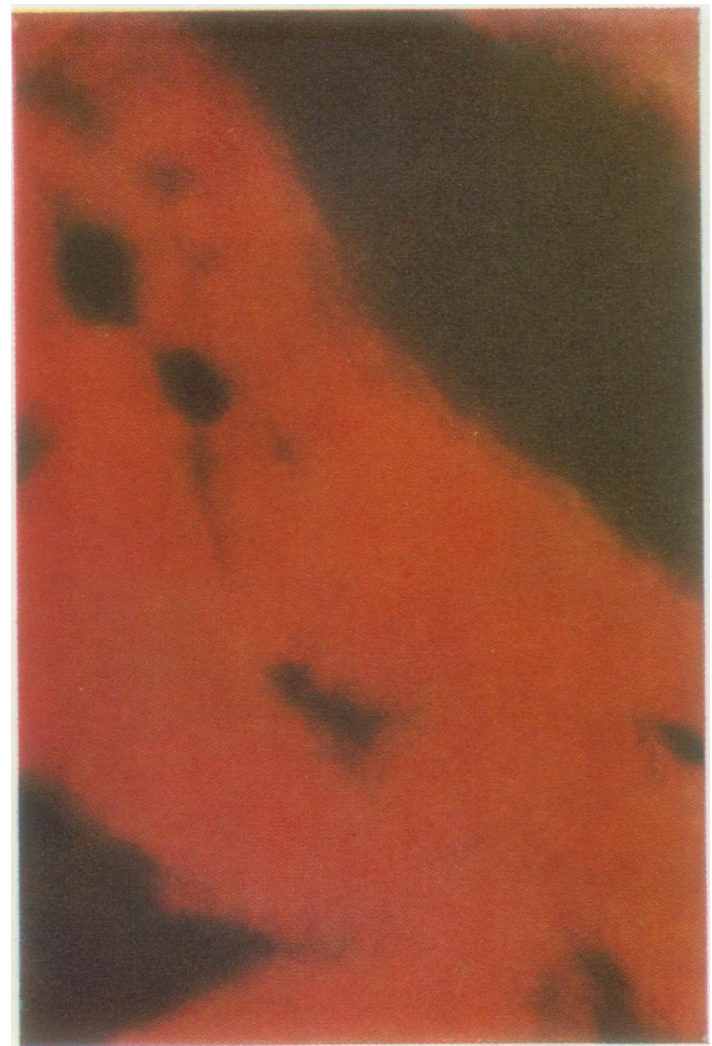

Fig 1c Rabbit heart muscle treated with normal human serum diluted 1:10 and fluorescein-labelled antihuman gamma globulin diluted 1:8. Counterstained with Evans blue. 1200 . fluorescence pattern in the muscle sections (fig la). The fluorescence intensity ranged from ++ at a serum dilution of $1: 8$ to $(+)$ at a dilution of $1: 128$ Correspondingly, a serum (myasthenia gravis 12), strongly reactive in the indirect haemagglutination test, produced a ++ fluorescence up to a dilution of $1: 64$, while at 1.256 the fluorescence was + . Using the direct IF technique, labelled $F\left(a b^{\prime}\right)_{2}$ prepared from normal human Ig produced fluorescence ranging in intensity from + at a dilution of $1: 8$ to $(+)$ at $1: 32$. The corresponding readings for $F\left(a b^{\prime}\right)$, prepared from serum myasthenia gravis 12 were ++ at $1: 8$ and $(+)$ at $1: 64$.

Absorption of sera or conjugates with rabbit liver or kidney tissue did not reduce the non-specific fluorescence. Thus, even with the use of pepsindigested sera-which after conjugation were absorbed with tissue-non-specific staining was too strong to allow satisfactory discrimination between positive sera and the negative control.

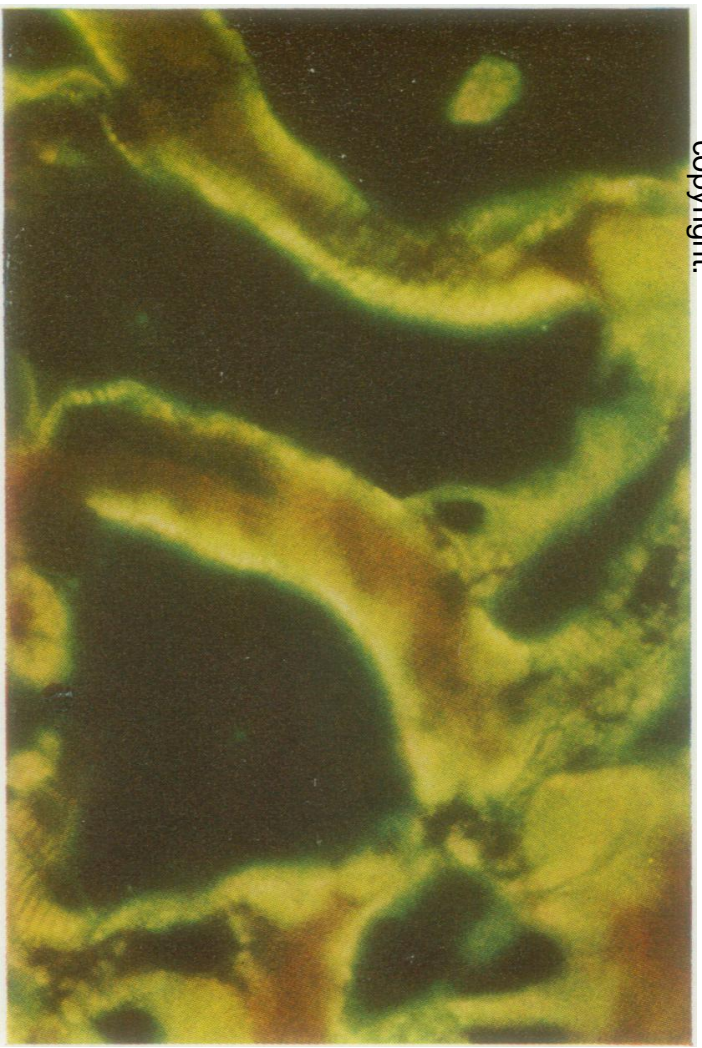

Fig 1d Rabbit heart muscle treated with serum myasthenic gravis 12 diluted $1: 10$ and fluorescein-labelled antihuman gamma globulin diluted 1:8. Counterstained with Evans blue. 1200 . 
The sections were then counterstained with $0 \cdot 1 \%$ Evans blue. In sections treated with normal human serum diluted 1:10 the fluorescence was, in most instances, completely abolished. This was particularly apparent at $160 \times$ magnification, while at a magnification of $1150 \times$ some trace of fluorescence could still be observed due to the greater sensitivity of the Opak system at the higher magnification. On the other hand, serum myasthenia gravis 12 used at the same dilution produced fluorescence of +++ . Experiments with various concentrations of Evans blue confirmed that a $0.1 \%$ solution produced the best results. Less satisfactory results were obtained if the dye was dissolved in phosphate-buffered saline. Figure 1 shows typical results with and without the use of Evans blue.

Blocking experiments, conducted earlier without conclusive results, were now repeated. One part of conjugated $F\left(a b^{\prime}\right)_{2}$ myasthenia gravis 12 was mixed with one part of PBS, citric acid-soluble muscle antigen, normal human serum or serum myasthenia gravis 12 , respectively, and incubated for 10 minutes at $37^{\circ} \mathrm{C}$. Each mixture was then used according to the staining procedure for the direct immunofluorescence technique. The intensity of the fluorescence was not reduced using PBS or normal human serum. When the conjugate was diluted in unconjugated serum myasthenia gravis 12 , the intensity of the fluorescence was greatly reduced. Dilution of the conjugate in a solution containing citric acid-soluble antigen almost completely abolished the fluorescence.

Similarly, with the indirect immunofluorescence technique, binding of myasthenia gravis $12 \mathrm{~F}\left(\mathrm{ab}^{\prime}\right)_{2}$ fragments was inhibited when citric acid-soluble antigen was mixed with the fragments before use. The results of these blocking experiments indicated that the citric acid-soluble antigen was mainly responsible for specific binding of serum myasthenia gravis $\mathbf{1 2}$ to skeletal muscle and that this antigen is localized mainly in the sarcolemmal or subsarcolemmal region. A more detailed interpretation of these results is published elsewhere (Aarli, 1972b).

The results of this modification of the indirect IF technique were compared with results using the indirect haemagglutination test with citric acidsoluble antigen. For immunofluorescence, sera were used at a dilution of $1: 10$, conjugate at a dilution of $1: 8$, and the preparations were examined at $160 \times$ magnification. As shown in fig 2 , positive sera were manifested by a bright fluorescent rim around the fibre bundles. The table gives a comparison of the results obtained with eight myasthenia gravis and eight normal human sera. Some sera, appearing as negative in the indirect haemagglutination test, showed positive immunofluorescence, indicating that antigens other than the citric acid-soluble

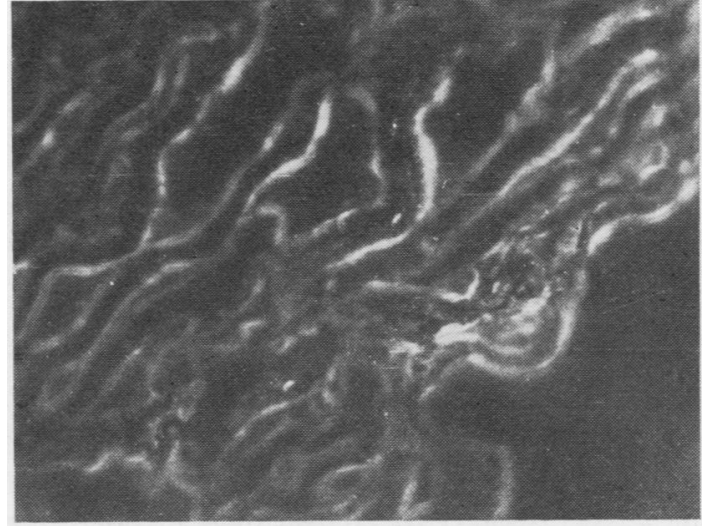

Fig 2 Rabbit skeletal muscle treated with serum myasthenia gravis 12 diluted 1:10 and fuorescein conjugatedantihumangamma globulin diluted 1:2. Strongly positive reaction with bright fluorescence at the outline of the muscle fibres. Counterstained with Evans blue. $160 \times$.

\begin{tabular}{lcc}
\hline $\begin{array}{l}\text { Myasthenia Gravis } \\
\begin{array}{l}\text { Serum } \\
\text { No. }\end{array}\end{array}$ & $\begin{array}{l}\text { Intensity of } \\
\text { Immunofluorescence }\end{array}$ & $\begin{array}{l}\text { Titre in Indirect } \\
\text { Haemagglutination }\end{array}$ \\
\hline 12 & $-(-)$ & 128000 \\
13 & $-(+)$ & 4096 \\
18 & $-(+)$ & 256 \\
25 & - & $<8$ \\
29 & $-(+)$ & 2048 \\
3 & $(+)$ & $<8$ \\
11 & $(+)$ & $<8$ \\
24 & $(+)$ & $<8$ \\
Eight normal sera & - & $<8$ \\
\hline
\end{tabular}

Table Antibodies to skeletal muscle: results of indirect immunofluorescence compared with titres in the haemagglutination test

antigen may also play a part in this reaction. Some myasthenia gravis sera produced only weak fluorescence, but no normal sera gave rise to fluorescence at this magnification. One serum (myasthenia gravis 25) produced a distinctly different pattern of fluorescence, characterized by prominent nuclear staining; this serum had previously been shown to contain antinuclear antibodies at a titre of 512. Thus, antinuclear antibodies are also detectable by the present technique.

\section{Discussion}

Non-specific binding of immunoglobulin or other proteins presents a problem when detecting muscle antibodies by immunofluorescence. Dilution of reagents and absorption of conjugate with tissue 
powder are the techniques usually employed to avoid non-specific staining. In the present experiments, these methods did not result in a sufficiently sensitive and specific IF system. Even the use of conjugated pepsin-digested sera did not abolish the non-specific staining.

Counterstaining with Evans blue in order to reduce non-specific staining was first reported by Nichols and McComb (1962). This method has since then been used successfully in a variety of immunofluorescence systems (Fry and Wilkinson, 1963; Boonpucknavig and Nairn, 1967; Ourth, 1971). In the present experiments, counterstaining of the sections in $0.1 \%$ Evans blue effectively reduce the non-specific fluorescence due to binding of normal human IgG to skeletal muscle. Following this treatment no fluorescence was se?n with normal sera at a magnification of $160 \times$. At the hignest magnification $(1200 \times)$ some very weak fluorescence could also be observed with normal sera, but it appeared to be diffuse compared with the fluorescent pattern produced by patient sera. While there was a reduction in the overall intensity of the fluorescence produced by positive sera following the counterstaining procedure, the pattern of fluorescence changed from a diffuse to a distinctly localized one.

The effect of Evans blue may be produced in several ways. The dye may act as a filter absorbing a certain percentage of the excitation light or of the fluorescence emitted by FITC. The absorption spectrum of Evans blue is given in figure 3. Although

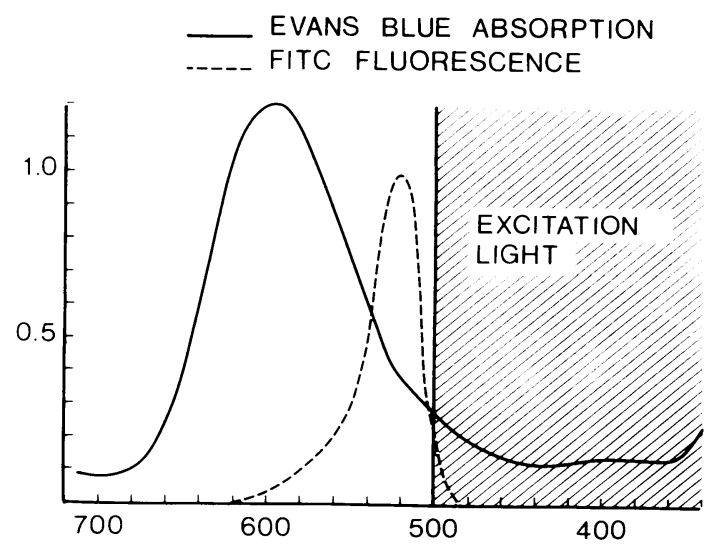

Fig 3 Diagram showing the relationship between the absorption spectrum of Evans blue, the emission spectrum of FITC (Nairn, 1969) and the maximum wavelength of the excitation light. Absorption and emission are given in arbitrary units. it shows very little absorption in the wavelength region of the excitation light $(300-500 \mathrm{~m} \mu)$ the dye absorbs in the region where FITC has its emission maximum (520-525 $\mathrm{m} \mu$ ), but this absorption is not very strong. Evans blue may therefore be postulated as having a filter effect which might result in a moderate reduction in the overall intensity of FITC fluorescence. If Evans blue has the same affinity for all components of muscle tissue absorption should reduce all FITC fluorescence by the same percentage. As weak fluorescence was observed to become more reduced than strong fluorescence, such absorption effects cannot explain the effect of the dye in the present experiments. If, on the other hand, Evans blue has a distinctly different affinity for various components of muscle tissue, its absorption would reduce the fluorescence in some areas of the muscle fibre more than in others. Such absorption would occur regardless of the specificity or non-specificity of the fluorescence, and the final pattern produced would depend on the distribution of Evans blue as well as on the initial binding of labelled conjugate. However, it seems very unlikely that the localization of fluorescence observed in the present experiments should be due to an artefact produced by Evans blue.

The deep red fluorescence emitted by Evans blue provides another explanation of the effect of the dye. All FITC fluorescence in the preparation is seen against a red background. The colour recognized by the observer will depend on the intensity of green versus red fluorescence in each area. In areas with weak FITC fluorescence the red colour will dominate while strong FITC fluorescence will stand out sharply against the red background. By offering better colour contrast, Evans blue may enhance localization of the strongest and presumably most specific fluorescence. Finally, the dye may reduce non-specific staining by competing for the same structures on the muscle fibres that are responsible for the binding of immunoglobulins by their Fc portion.

In the present study sera from patients with myasthenia gravis produced fluorescence in the sarcolemmal or subsarcolemmal region and corresponding to the transverse striations of the muscle fibres. Blocking experiments indicated that the citric acid-soluble antigen is localized mainly in the sarcolemmal region. Sera which were strongly positive in IF also gave high titres in the indirect haemagglutination test with citric acid-soluble antigen. However, whereas only half of the patient sera were positive in the haemagglutination test, all were positive in immunofluorescence. The present modification of the immunofluorescence technique may therefore provide a useful test for the detection of muscle antibodies. 
References

Aarli, J. A. (1970). Binding of $\gamma$-globulin fragments to muscle tissue. Clin. exp. Immunol., 7, 23-30.

Aarli, J. A. (1972a). Myasthenia gravis. Antibodies to an acid-soluble antigen in striated muscle. Clin. exp. Immunol., 10, 453-461.

Aarli, J. A. (1972b). Localization and properties of an acid-soluble muscle antigen reacting with antibodies in myasthenia gravis sera Acta. path. microbiol. scand., Sect. B, 80, 453-459.

Aarli, J. A., and Closs, O. (1972). Myasthenia gravis: Cross-striational fluorescence of muscle fibres mediated by Fc-fragments. J. Immunol., 109, 271-274.

Boonpucknavig, S., and Nairn, R. C. (1967). Serological diagnosis of amoebiasis by immunofluorescence. J. clin. Path., 20. 875-878.

Espinosa, E., and Kaplan, M. H. (1968). Antigenic analysis of human heart tissue. Identification of antigens with specificity re- stricted to heart and skeletal muscle in acid extracts of myocardium. J. Immunol., 100, 1020-1031.

Fry, C. S., and Wilkinson, A. E. (1963). A note on the use of Evans blue as a background stain in the fluorescent treponemal antibody test. Brit. J. vener. Dis., 39, 190-191.

Larsen, B., and Tönder, O. (1969). Preparation of anti-human- $\gamma$-globulin serum not containing human serum proteins. Vox Sang. (Basel), 16, 69-72.

Lowry, O. H., Rosebrough, N. J., Farr, A. L., and Randall, R. J (1951). Protein measurement with the Folin phenol reagent. J. biol. Chem., 193, 265-275.

Nairn, R. C. (Editor) (1969). Fluorescent Protein Tracing, 3rd ed. Livingstone, Edinburgh and London.

Nichols, R. L., and McComb, D. E. (1962). Immunofluorescent studies with trachoma and related antigens. J. Immunol., 89, 545-554.

Ourth, D. D. (1971). An immunofluorescent test for Toxoplasma gondii in tissues. Immunology, 20, 437-439.

\section{The January 1974 Issue}

\section{THE JANUARY 1974 ISSUE CONTAINS THE FOLLOWING PAPERS}

\section{A New Year Greeting w. H. AUDEN}

A review of the pathology and pathogenesis of acute renal failure due to acute tubular necrosis $M$. $\mathbf{S}$. DUNNILL

The demonstration of plasma cells and other immunoglobulin containing cells in formalin-fixed, paraffin-embedded tissues using peroxidase-labelled antibody C. R. TAYLOR AND J. BURNS

Diffuse and focal oxygen pneumonitis SIMON SEVITT

Mast cells in parathyroid glands of hyperparathyroidism T. J. ANDERSON

Evaluation of a solid phase radioimmunoassay (Ausria-125) for the detection of hepatitis B antigen (Australia antigen) in two clinical materials B. G. HANSSON AND T. JOHNSSON

Latex agglutination test for detection of Australia antigen (HB-Ag) among blood donors and patients R. HOPKINS AND P. C. DAS

Alloantibodies and Australia antigen after open heart surgery S. D. SLATER

Torulopsis glabrata urinary tract infection treated with 5-fluorocytosine

D. C. E. SPELLER
The treatment of acute myeloid leukaemia J. H. FRIEND, C. GILES, AND S. G. N. RICHARDSON

Normal laboratory values for differential white cell counts established by manual and automated cytochemical methods (Hemalog $D^{\text {TM }}$ ) A. SIMMONS, P. LEAVERTON, AND G. ELBERT

Experience with a commercial kit for the radioisotopic assay of vitamin $B_{12}$ in serum: the Phadebas $B_{12}$ Test J. L. RAVEN AND M. B. ROBSON

Candida precipitins in pregnant women: validity of the test systems used VALERIE C. STANLEY AND ROSALINDE HURLEY

A simple method for detecting mycoplasma infection of cell cultures G. B. HARNETT, P. A. PHILLIPS, AND E. M. MACKAY-SCOLLAY

The estimation of serum thyroxine by competitive binding analysis: A modified method D. J. GOLDIE, R. D. JENNINGS, AND G. K. MCGOWAN

\section{Technical method}

A venepuncturing chair suitable for an outpatient department or laboratory blood collecting room P. H. EVERALL AND PATRICIA A. WYCHERLEY

Letter to the Editor

Book reviews

Copies are still available and may be obtained from the PUBLISHING MANAGER, BRITISH MEDICAL ASSOCIATION, TAVISTOCK SQUARE, LONDON WClH 9JR, price $£ 1.05$ 